\title{
PIO DAMIÃO: A ENFERMAGEM COMO FORMA DE PARTICIPAÇÃo POLÍTICA
}

\author{
PIO DAMIÃO: NURSING AS A FORM OF POLITICAL PARTICIPATION
}

PIO DAMIÃO: LA ENFERMERÍA COMO FORMA DE PARTICIPACIÓN POLÍTICA

Recebido: 13/01/2015

Aprovado: 20/11/2015

\author{
Maria Regina Guimarães Silva1 \\ Maria Cristina Sanna ${ }^{2}$
}

Esta é uma pesquisa sócio-histórica que tem como objetivo identificar, descrever e analisar a trajetória profissional de Pio Damião. No estudo foram empregados documentos cartoriais, livro-ata de reuniões da Santa Casa, testamento público, artigos de revistas e jornais da época e, documentos do Arquivo Público Mineiro. Como fontes indiretas, foram utilizados capítulos de livros que retratam a história da cidade e que também citaram Pio Damião. Os documentos foram submetidos a leituras repetidas para busca das informações e do estabelecimento das relações entre elas. O personagem em foco foi o primeiro "enfermeiro" a trabalhar na Santa Casa de Guaxupé, Minas Gerais. Iniciou suas atividades em 1913, se dedicando à enfermagem, cozinha e lavanderia da instituição. Fundou a Frente Negra Brasileira em Guaxupé. Foi desligado da Santa Casa provavelmente por motivos religiosos, por não ser católico, e permaneceu prestando cuidados à população da cidade em seu próprio domicílio até seu adoecimento e morte, em 1953.

Descritores: História da enfermagem; Prática profissional; Biografia.

This socio-historical research was conducted in order to identify, describe and analyze Pio Damião's professional career. The study was based on direct sources such as notarized documents, meeting minute books, a public will, news articles of that period and documents from the Public Archive of Minas Gerais, Brazil. Chapters of books which portray the changes in the town and also mention Pio Damião were used as indirect sources. The documents and publications were repeatedly studied in the search for information and its relations. The subject studied was the first "nurse" to ever provide nursing care at Guaxupé's Charity Hospital, Minas Gerais, Brazil. He began his work in 1913, involving himself in the nursing, cooking and laundry activities at the institution. He founded the Brazilian Black Front in Guaxupé, but, was dismissed from the Charity Hospital, supposedly for a religious matter - he was not Catholic - but continued to provide healthcare services to the population at his own house until his sickness and death, in 1953.

Descriptors: History of nursing; Professional practice; Biography.

Esta es una investigación socio histórica con el objetivo de identificar, describir y analizar el trayecto profesional de Pio Damião. Para el estudio se utilizaron, como fuentes directas, documentos de archivos, libro de actas de reuniones de la Santa Casa, testamento público, artículos de revistas y periódicos de la época y documentos del Archivo Público de Minas Gerais, Brasil. Como fuentes indirectas, fueron utilizados capítulos de libros que relatan la historia de la ciudad y que también se citaron Pio Damião. Los documentos fueron sometidos a lecturas para buscar informaciones y establecer relaciones entre ellas. El personaje en el foco fue el primero "enfermero" a proporcionar sus servicios en la Santa Casa de Guaxupé, Minas Gerais, Brasil. Empezó sus actividades en 1913, dedicándose a los cuidados de enfermería, cocina y lavandería de la institución. Fundó la Frente Negra Brasileña en Guaxupé. Fue encedido de la Santa Casa probablemente por razones religiosas, puesto que no era católico, pero permaneció prestando cuidados a la populación de la ciudad en su proprio domicilio hasta su enfermedad y muerte, ocurridos en 1953.

Descriptores: Historia de la enfermería; Práctica profesional; Biografía.

\footnotetext{
${ }^{1}$ Enfermeira. Especialista em Saúde Coletiva. Especialista em Enfermagem do Trabalho. Mestre em Ciências da Saúde. Doutoranda em Ciências da Saúde pela Escola Paulista de Enfermagem da Universidade Federal de São Paulo - UNIFESP - bolsista do CNPq.É membro do Grupo de Estudos e Pesquisa em Administração em Saúde e Gerenciamento em Enfermagem - GEPAG, credenciado no CNPq.reginagsilva@uol.com.br

2 Enfermeira.Especialista em Enfermagem de Saúde Pública. Licenciatura em Enfermagem. Mestre em Enfermagem. Doutora em Enfermagem.Pós-Doutorado em Enfermagem. É pesquisadora independente e membro do corpo permanente de orientadores do Programa de Pós-graduação em Enfermagem da Escola de Enfermagem da UNIFESP desde 2005. É membro do GEPAG e, líder do Centro de Estudos e Pesquisas sobre História da Enfermagem (CEPHE).mcsanna@uol.com.br
} 


\section{INTRODUÇÃO}

A cidade de Guaxupé, localizada no estado de Minas Gerais foi fundada em 1837, quando Paulo Carneiro Bastos doou vinte e quatro alqueires de terra, à Igreja Católica, para a constituição do patrimônio da capela em louvor a Nossa Senhora das Dores do Guaxupé. Na época, as fazendas ao redor da cidade produziam grande quantidade de café e tinham escravos como mão de obra, além dos primeiros imigrantes, que buscavam ocupação na agricultura cafeeira ${ }^{1}$.

Mais tarde, na primeira década do século XX, algumas fazendas já possuíam telefone, máquinas de beneficiar café e veículos próprios para a utilização na lavoura, como tratores. Com a alta produção e o investimento de alguns barões do café, o progresso foi se acelerando, sendo consolidado com a chegada da estrada de ferro. A economia cafeeira impulsionou o crescimento geográfico, a imigração e a urbanização de Guaxupé, trazendo muitas demandas de serviços para a cidade ${ }^{2}$. As estações da estrada de ferro atraíram imigrantes italianos, espanhóis, síriolibaneses e trabalhadores brasileiros de outras cidades e estados, despertando interesse pela cidade e ampliando sua ocupação, o que teve, como consequência, seu crescimento.

Com o aumento da população, falta de condições de higiene e de assistência médicosanitária, doenças infectocontagiosas assolaram a cidade, trazendo a necessidade de criação de um serviço de saúde, para prestar atendimento aos colonos das fazendas e operários da rede ferroviária que adoeciam. Assim, em junho de 1910, foi inaugurada a Santa Casa de Misericórdia de Guaxupé. Na cidade havia poucos médicos que atendessem às necessidades dos doentes e, naquele tempo, a oferta de cursos de formação de enfermeiros era quase inexistente, lembrando-se que a Enfermagem, na época,tinha base empírica e não era ensinada em escolas ou reconhecida como ciência.

As primeiras iniciativas de se instituir o ensino de enfermagem no Brasil,no estado do Rio de Janeiro, datam de 1890, com a criação da Escola Profissional de Enfermeiros e Enfermeiras da Assistência a Alienados, atual Escola de Enfermagem Alfredo Pinto, pertencente à Universidade Federal do Estado do Rio de Janeiro (UNIRIO) ${ }^{3}$.

Em São Paulo, a primeira escola criada para profissionalizar enfermeiras foi fundada em 1894, no Hospital Samaritano. O curso tinha três anos de duração e era ministrado em regime de internato e as primeiras professoras contratadas foram formadas na Inglaterra 4 .

Em Minas Gerais, não há registros de escolas de enfermagem antes de 1933, quando foi criada a Escola Carlos Chagas, em Belo Horizonte, atualmente pertencente à Universidade Federal de Minas Gerais.O país experimentava o crescimento econômico e social republicano, mas tinha mínimos investimentos nas escolas formadoras de profissionais de enfermagem. Nesse cenário, Guaxupé não oferecia qualquer curso preparatório para enfermeiros, mas,com o aumento populacional e a chegada dos imigrantes, houve um surto de febre tifoide que acometeu vários trabalhadores da rede ferroviária e também colonos, que buscaram atendimento no único hospital da cidade, o que demonstrou a necessidade de profissionais capazes de atuar nessa situação.

Com poucos médicos e apenas uma "enfermeira", Rosa Sanchetta, a Santa Casa registrou o atendimento de 27 doentes, no período de fevereiro de 1911 a abril de $1912^{\mathrm{D} 1}$. Sobre essa "enfermeira" pouco se sabe além de seu nome, mas, no ano seguinte, importante personagem da história da cidade - Pio Damião, chega a Guaxupé para nela residir durante quarenta anos, período em que se dedicou às atividades de enfermagem e à política.

Considerando-se a contribuição desse ator social para a comunidade guaxupeana e a oportunidade de, através do estudo de sua trajetória profissional, favorecer 0 entendimento de como se deram as práticas de enfermagem e a participação política em cidades da região sudeste, cuja história foi influenciada pela produção e comercialização 
de café, resolveu-se realizar o presente trabalho, cujo objetivo é identificar, descrever e analisar a trajetória profissional de Pio Damião.

\section{MÉTODO}

Estudo histórico-documental, cujas fontes diretas foram: Escritura Pública de compra de duas casas por Pio Damião, registradas no Livro no37, fls. 19 a 20, de 19/11/1915 e Livro no40, fls. 79 a 80, de 08/01/1917;Lei Municipal no637/1974 que dispõe sobre denominação de rua;Livro-ata $\mathrm{n}$ o $\mathrm{I}$ de reuniões da Santa Casa;Esboço de partilha de bens registrado no Cartório do $1^{\mathrm{o}}$ Oficio de Muzambinho-MG em 10/02/1917; testamento público de Pio Damião, registrado no Cartório do 1ํ Ofício de Guaxupé-MG em 16/01/1953; artigos de revistas e jornais da época e documentos registrados na pasta número 4643 do acervo do Arquivo Público Mineiro, referente ao Movimento da Frente Negra Brasileira.

Como fontes indiretas foram analisados capítulos de livros que retratam a transformação da cidade e que também citaram Pio Damião. A coleta de dados ocorreu no período de novembro de 2012 a dezembro de 2013. Os documentos foram organizados em bases de dados física e eletrônica e agrupados por similaridade e pertinência temática, em ordem sequencial dos acontecimentos vivenciados pelo personagem em foco.

Este estudo obteve a aprovação do Comitê de Ética da Santa Casa de Guaxupé e do Comitê de Ética da Universidade Federal de São Paulo - UNIFESP, sob o Parecer $n^{\circ}$ 354.873 .

\section{RESULTADOS}

A partir da análise dos documentos e a organização dos dados históricos se construiu as categorias de análise, a saber: vida pessoal, trajetória profissional e militância política, que foram descritas e discutidas à luz da literatura científica disponível sobre o tema e os conceitos da Teoria do Mundo Social de Pierre Bourdieu.

\section{DISCUSSÃO}

Em 25 de dezembro de 1882, na cidade de Araxá, interior de Minas Gerais, nasceu Pio Damião. Filho dos escravos Tobias Damião e Eva Maria, tinha duas irmãs: Rosária Teodoro Damião e Suzana Damião ${ }^{\mathrm{D} 2}$, todos nascidos livres por efeito da Lei do Ventre Livre. Essa lei foi assinada por Dom Pedro II em 1871 e, segundo ela, não haveria de nascerem mais escravos no Brasil, o que significava a abolição gradual da escravatura que se estendeu até a promulgação da Lei Áurea assinada pela Princesa Isabel, em 13 de maio de 1888, libertando todos os escravos restantes ${ }^{1}$.

0 movimento abolicionista se estendeu por todo o país na década de 1880, antes mesmo da promulgação da Lei Áurea. Até então, o que havia eram tentativas emancipatórias que queriam a extinção gradual do trabalho escravo enquanto os abolicionistas desejavam a supressão total e imediata da escravidão. Algumas iniciativas particulares,disseminadas, por todo o país tiveram destaque ao fim da escravatura como a criação de sociedades antiescravistas e emancipadoras, e a Lei Saraiva-Cotegipe, de 1885, que libertava os escravos com mais de 65 anos de idade. No sul de Minas Gerais, o movimento abolicionista eclodiu, atingindo regiões onde 0 trabalho escravo era indispensável à produção agrícola, sobretudo a agricultura cafeeira ${ }^{1}$.

A despeito disso, em Guaxupé, o primeiro ato de abolição da escravatura ocorreu em 12 de maio de 1881, pelo Tenente Coronel Manoel Joaquim Ribeiro do Valle, mais tarde agraciado por Dom Pedro II com o título de Barão das Dores do Guaxupé, que teve a iniciativa de libertar seus 16 escravos e, após entendimento com seus familiares fazendeiros, com eles restituiu a liberdade a mais 186 escravos $^{1}$.

Damião, que nasceu livre nesse mesmo estado, casou-se com Jerônima Damião, mas não tiveram descendentes ${ }^{\mathrm{D} 2}$. Ainda jovens, a convite do engenheiro Oliveira Martins, fixaram residência em Guaxupé, a fim de Damião trabalhar na construção da rodovia GuaxupéMuzambinho, como ajudante do referido 
engenheiro $^{\mathrm{D} 3}$. Ao término da obra, Damião trabalhou como cozinheiro da Companhia Mogiana de Estradas de Ferro, época de expansão da malha ferroviária no Brasil.

A estrada de ferro trouxe o primeiro trem a Guaxupé em 1904, colaborando para o progresso da cidade não só através do escoamento da produção cafeeira, mas pelo intercâmbio de pessoas e produtos, inclusive os culturais, já que a ferrovia era tratada, à época, como o veículo condutor da civilização ${ }^{1}$. A cidade foi se transformando à medida que chegavam os imigrantes, que também impulsionaram o comércio local. Com o aumento da população e a ocorrência do surto de febre tifoide já citado, que contaminou vários operários da rede ferroviária, a Santa Casa foi inaugurada para atender à necessidade daqueles trabalhadores.

Com poucos médicos e apenas uma enfermeira, a necessidade de assistir aos pacientes internados fez com que Pio Damião assumisse o cargo de zelador do hospital, colaborando com a cozinha, lavanderia e serviços de enfermagem. Concomitantemente, sua esposa, Jerônima Damião, assumiu o ofício de parteira. Ambos se dedicaram ao trabalho hospitalar, praticando a enfermagem empírica e cuidando da instituição. Atuaram na prestação de serviços sem remuneração financeira, no período de março de 1913 a fevereiro de 1914, residindo nas dependências da Santa Casa. Posteriormente, com a organização do hospital, Damião passou a receber a quantia de trezentos e sessenta mil reis $(360 \$ 000)$ mensais mais um mil reis diário por doente internado na instituição ${ }^{\mathrm{D} 4}$.

0 valor estimado desse rendimento equivalia, à época,a oito novilhos ou aproximadamente 4.000 pés de café novos, que custavam $400 \$ 000$ (quatrocentos mil reis). Uma casa para moradia de colonos, construída de madeira, valia $50 \$ 000$ (cinquenta mil reis), mas, se a casa fosse construída com tijolos e telhas, também para colonos, custava 220\$000(duzentos e vinte mil reis). Um carro de boi era avaliado em $90 \$ 000$ (noventa mil réis) e uma máquina de moer grãos valia 200\$000 (duzentos mil réis). Esses dados foram registrados no Cartório de Muzambinho ${ }^{\mathrm{D} 5}$ em 1917 e, referem-se ao espólio de um cidadão guaxupeano que, dentre outros bens, era proprietário de uma casa no centro da cidade, no valor de 3:500\$000 (três contos e quinhentos mil réis).

Como se vê, Damião exerceu funções assistenciais e gerenciais no hospital e,como reconhecimento por seu trabalho, recebia remuneração mista em que surpreendentemente figurava parcela de "produtividade". Interessante notar que o personagem em foco exercia mais de uma função que lhe permitia acumular capital social e político, pois o recurso financeiro que auferia era em parte revertido para obra social que dava visibilidade para sua liderança.

Pio Damião comprou seu primeiro imóvel em novembro de 1915. A casa localizava-se na Rua Vieira do Valle, era construída de madeira e tijolos, tinha uma janela de frente e uma porta de entrada ao lado dessa janela. 0 quintal tinha algumas plantações e também uma cisterna. Posteriormente, nesse mesmo local, foi inaugurada a sede da Frente Negra Brasileira, em Guaxupé, fundada por ele ${ }^{\mathrm{D} 6}$.

0 segundo imóvel de Damião foi registrado no Cartório de Guaxupé - uma casa na Rua da Porteira. Construída de tijolos e coberta de telhas, tinha uma porta e uma janela e, ao fundo, confrontava-se com a Santa Casa. Com espírito empreendedor, Damião fundou uma empresa funerária "Empresa Funerária Pio X", em oito de junho de 1928, anexa à sua residência. Parte da quantia arrecadada, $16 \%$ da venda dos caixões, era revertida para a Santa Casa ${ }^{\mathrm{D7}, \mathrm{D} 8}$. Naquela época era comum as Santas Casas receberem doações diversas e porcentagens de funerais que subsidiassem a manutenção dessas instituições. Damião, percebendo essa condição, passou a administrar o próprio negócio, aumentando seu aporte de recursos financeiros.

Quando Damião deixou de prestar seus serviços à Santa Casa, reservou um "quarto" em sua residência para abrigar 
pacientes considerados desenganados pelos médicos, ou indigentes e deficientes físicos (crianças ou adultos), dando-lhes comida e pouso até que seguissem um caminho em suas vidas. Nesse local, praticava cuidados referentes à "administração de medicamentos, aplicação de injeções e curativos". Pio também não descuidava da assistência espiritual aos doentes que atendia na Santa Casa, ouvindo-os e confortando-os, tratando a todos com solicitude, igualdade de carinho e interesse pelo pronto restabelecimento da saúde de cada um dos doentes. Por seus feitos, foi reconhecido na cidade, principalmente pela abnegação dos próprios interesses em função de atender ou satisfazer as necessidades alheias. Não deixou descendente, mas criou filhos adotivos e foi padrinho de muitos casais e crianças ${ }^{5}$. Damião foi reconhecido pelo atendimento integral prestado aos mais necessitados e também pela atitude de liderança que exercia na função de "enfermeiro", atendendo os pacientes em sua própria residência. Assim, a função de "enfermeiro" lhe deu visibilidade e reconhecimento social e político.

Importante mencionar que os dois imóveis adquiridos por Damião eram separados apenas por uma cerca de arame e que as ruas da Porteira e Vieira do Valle são atualmente unificadas e receberam o nome de Francisco Vieira do Valle, estando localizada próxima à Santa Casa, na região central de Guaxupé.

Damião foi citado na Ata da Assembleia Geral da Santa Casa de fevereiro de 1919D9 como enfermeiro atencioso e dedicado, que dispensava atenção aos doentes internados sem qualquer distinção de classe social, auxiliava na alimentação, higiene e curativos. No mesmo evento foi registrado $\mathrm{o}$ atendimento de mais de trezentos doentes provenientes da cidade de Guaxupé, da zona rural e dos municípios vizinhos no triênio que se encerrara no ano anterior.Pelo recenseamento de 1920, a população de Guaxupé era composta de 16.701 habitantes, sendo 8.427 homens e 8.274 mulheres, o que significa dizer que cerca de $6 \%$ da população era atendida por ano naquela instituição.Como o tratamento preferencial na época não era feito sob regime de internação, este número pode ser considerado expressivo. As doenças mais registradas na época eram a tuberculose, a lepra, a febre tifoide e a pneumonia6.

Um ano depois, ocorreu a décima oitava Reunião Administrativa da Santa Casa,presidida por Dom Ranulpho da Silva Faria, Bispo da Diocese de Guaxupé, a convite do provedor, Major Custódio Ribeiro Ferreira Leite. Esse encontro teve o objetivo de eleger a nova mesa administrativa do hospital que serviria ao biênio de 1921 a 1922, demonstrando estreita relação entre a direção do hospital e o representante da Igreja Católica. Nesse mesmo evento, o corpo diretivo proferiu um voto de louvor a Pio Damião pelos serviços prestados na instituição como reconhecimento de sua atenção aos doentes internados na Santa CasaD10. Considerando-se que os fundadores e colaboradores da Santa Casa exerciam atividade política na região, infere-se que valorizaram os serviços prestados por Damião porque ele poderia ser um elo com aproximação das pessoas mais carentes, influenciando a opinião pública quanto às atividades políticas partidárias na cidade.

A reunião seguinte contou com a participação de Pio Damião e teve, como pauta, a eleição da diretoria para o biênio de 1923 a 1924. Foi o único "enfermeiro" citado na ata desse evento, do qual também participaram o padre José Garciândia, o provedor, médicos e mesários. A eleição foi feita por aclamação e o Coronel Joaquim Augusto Ribeiro do Valle apresentou a lista que compunha aquela diretoria, determinando a seguinte nomeação: major Custodio Ribeiro Ferreira Leite com o cargo de provedor, Aristides Barbosa de Oliveira como mordomo, Capitão Francisco Augusto Ribeiro do Valle como tesoureiro, Martiniano Prado Filho como procurador e Antonio Lopes Pereira como secretário. Para mesários foram eleitos: Luiz Ribeiro do Valle, Esmerino Ribeiro do Valle, Manoel Gonçalves Ferraz, Américo Ribeiro Costa, Agenor Alves de Araújo, Eleusippo Epaminondas de Castro, Eurico Távora Barretto, Eduardo de Oliveira, 
Horacio Ferreira Lopes, Antonio Christino Lara, Padre Jose Garciândia e Jesuino Costa Monteiro ${ }^{\text {D11. } 0}$ corpo diretivo da instituição era composto pela elite guaxupeana, destacando-se os fazendeiros, os políticos, os médicos, os advogados e membros da Igreja Católica, desde o início das atividades da Santa Casa de Guaxupé.

0 anúncio no jornal da cidade assinado por José E. Diniz Carneiro em 24 de fevereiro de 1924, recém-estabelecido de sua enfermidade, fazia ato de reconhecimento ao atendimento de enfermagem prestado por Pio Damião na Santa Casa de Guaxupé, descrevendo-o como "alma bondosa e benfazeja, enfermeiro incomparável, hábil e caridoso"7.

As atividades profissionais de Damião desenvolvidas a partir da enfermagem como centro lhe permitiam reforçar seu carisma, o que o levou a alcançar uma projeção política de destaque, como se vê no reconhecimento público que recebeu.

Na Santa Casa, Damião desempenhava as funções básicas de enfermagem e também as específicas, conforme registro no I Livro de Enfermos da Santa Casa, em que auxiliou o médico Orlando Vairo na cirurgia de extirpação de "cistos sebáceos da cabeça", realizada em janeiro de $1928^{8}$. Sua atividade profissional era dividida entre a prestação de assistência e administração da Santa Casa, mas a presença ao lado do doente internado era marcante.

Nova reunião da diretoria foi realizada em julho de 1923, de que Pio Damião também participou. A pauta se referia "às péssimas condições financeiras do estabelecimento", e ficou decidido que somente as pessoas consideradas indigentes teriam atendimento gratuito e que,dos enfermos provenientes das propriedades rurais, seria cobrado o pagamento da diária no valor de $4 \$ 000$ (quatro mil reis), a ser pago pelo proprietário da fazendaD12. 0 valor estimado de um bezerro à época era de $30 \$ 000$ (trinta mil reis), conforme Esboço de Partilha de João Carlos de Magalhães Gomes, registrado no Cartório de Muzambinho em fevereiro de 1917,o que permite inferir que o valor de uma diária na Santa Casa era uma quantia irrisória para os proprietários das fazendas ${ }^{\mathrm{D} 5}$.

Embora com dificuldades financeiras, a Santa Casa registrou o atendimento de 234 pacientes no ano de 1923; destes, apenas 27 foram internados em quartos particulares. Os outros 207 enfermos utilizaram o serviço das enfermarias do hospital, que ficavam sob a responsabilidade de Pio Damião ${ }^{8}$.Provavelmente, esse episódio fez com que, com sua visão empreendedora, vislumbrasse a possibilidade de oferecer serviços próprios aos necessitados que não tivessem proprietários das fazendas para pagar por eles e, amealhar contribuições, ainda que pequenas, para a entidade assistencial que ele mesmo viria a dirigir mais tarde.

Com a transformação da cidade, outras instituições sociais e de saúde foram criadas na década de 1920, como a Sociedade de São Vicente de Paulo, o Lar São Vicente, que tinha, como proposta, abrigar portadores de hanseníase e tuberculose, e a Casa de Saúde Santa Terezinha. 0 primeiro Centro de Saúde de Guaxupé foi inaugurado em 1938 e,em 1994, passou a denominar-se Centro Diagnóstico Pio Damião, estabelecimento público de saúde que oferece atualmente, à população, consultas médicas e de enfermagem, sala de vacinação, exames laboratoriais e de imagem ${ }^{1}$.

O cenário educacional da cidade na década de 1920 contava com ensino teórico e prático ministrado em vários estabelecimentos como o Grupo Escolar "Dr. Delfim Moreira", o Colégio Diocesano São Luiz Gonzaga, e a Academia de Comércio São José, que formava guarda-livros e contadores e recebia subvenção do Estado. O Instituto Profissional Nossa Senhora do Carmo, que "abrigava órfãos, descobria a vocação dos meninos e jovens e ensinavam-lhes uma profissão". O aprendizado Agrícola Dom Assis, o Colégio da Imaculada Conceição, o Externato Rocha e a Escola Della Societá Itália Unita eram os outros estabelecimentos de ensino, todos particulares. Os primários municipais rurais estavam localizados nas fazendas circunvizinhas a Guaxupé e a maioria delas era de propriedade dos 
fundadores e colaboradores da Santa Casa. Funcionavam nas fazendas Bom Jardim, Barra, Três Barras, Santa Maria, Córrego Fundo, Cardosos, Pintos, Santa Rosa, Jaboticabeiras, Cala Bocca e Santa Cruz. Existiam também os primários particulares rurais, localizados nas fazendas Serra, dos Machados, do Jaboty e Epitácio Pessoa. Grande número de pacientes atendidos na Santa Casa era proveniente dessas fazendas ${ }^{9}$.

Na mesma década foi criado o serviço de saneamento da cidade; o abastecimento de água e a rede de esgotos foram projetados pelos engenheiros João Ferraz, Antonio Machado de Campos e J. Amaral Gurgel. Outros importantes serviços foram instalados na cidade, como o Centro Telefônico e o Banco do Brasil ${ }^{1}$.Alguns clubes também foram fundados no município no mesmo período, como a Sociedade Recreativa Clube Guaxupé, que iniciou suas atividades em 1926,promovendo bailes e tinha, como proposta, fomentar o desenvolvimento do automobilismo e incentivar a construção e o melhoramento das rodovias mineiras. A Associação Atlética Guaxupé, outra agremiação social, também promovia bailes aos domingos e bailes carnavalescos. Mais tarde, em julho de 1935, foi fundado o Guaxupé Country Clube, com a proposta de oferecer, aos guaxupeanos, um clube de esportes, inclusive com a construção de uma piscina ${ }^{1}$.

Alguns desses clubes não permitiam a entrada de negros e, em 1938, Damião fundou a Frente Negra Brasileira, com sede em Guaxupé, um movimento político relevante que tinha, como lema, a inclusão do povo negro na sociedade brasileira. Nessa instituição ocupou o cargo de delegado e fiscal geral de Minas Gerais ${ }^{10}$. A entidade mantinha uma escola noturna com cursos profissionalizantes e era mantida exclusivamente com as quotas dos sócios. Com rígida disciplina, tinha como proposta valorizar o negro para sua futura ascensão social e profissional, além de unificar e protegê-los. Em Guaxupé, esse clube social organizava bailes para os negros, além de ensinar boas maneiras e noções de bordado e costura às integrantes da Associação ${ }^{5}$.
Percebe-se que as questões políticas e a vida social dos negros guaxupeanos eram uma inquietação constante para Damião, que tinha como proposta oferecer, a este grupo de pessoas, novos valores e práticas, buscando a ascensão social dos negros. Isso se dava, na visão de Pio Damião, pela aquisição de capital cultural da classe dominante, o que permitiria o ingresso dos negros em ambientes, senão próprios daquela classe, análogos a esses.Essa estratégia garantiria dar visibilidade aos negros e oferecer-lhes o mesmo que os brancos tinham, num processo de assimilação da cultura dominante: ao mesmo tempo que apostava na ascensão pela acumulação de capital cultural e valores e práticas da classe social mais elevada, tornava o segmento negro pronto para nela ingressar ou, pelo menos, servir a ela.

O movimento político da Frente Negra Brasileira foi criado em 16 de setembro de 1931, na cidade de São Paulo, sob a presidência de Arlindo Veiga dos Santos e,em 1936, foi inscrito no Superior Tribunal Eleitoral como partido político, expandindose para várias cidades brasileiras. Pio Damião ficou na liderança dessa associação em Guaxupé até que o presidente Getúlio Vargas extinguisse o movimento, pois os partidos políticos foram considerados ilegais na época, ainda mais porque essa associação era considerada "comunista"6-11.

Damião não mediu esforços para manter o movimento frente-negrino em Guaxupé. Uma dessas evidências é o documento enviado ao chefe de polícia de Minas Gerais, Ernesto Dornellas, em que descreveu os objetivos da Frente Negra, alegando que o partido não era da "esquerda" e solicitava manter o movimento ativo, oferecendo aos negros pelo menos as atividades recreativas, após a dissolução dos partidos. 0 pedido, porém, foi negado ${ }^{10}$.

Assim, em Guaxupé, após a determinação do governo para encerrar as atividades da Frente Negra Brasileira, foi criado um novo movimento, aos 13 de maio de 1954,um ano após a morte de seu fundador - a Sociedade Negra Recreativa Pio Damião, sediada à Rua Francisco Vieira do 
Valle, no152, mesma sede da antiga associação. Conforme o estatuto dessa sociedade, a primeira diretoria foi constituída pelo presidente José Ormindo Tavares, o vice-presidente Austim Paulino dos Santos, o primeiro secretário, Raimundo de Macedo Filho, o segundo secretário, Arlindo Souza Mendes, o tesoureiro Eurípedes Tobias e um conselho fiscal formado por 12 sócios. 0 objetivo da nova Sociedade Negra Recreativa era "conjugar toda a força social em favor da elevação moral, intelectual, artística, assistencial e proteção aos seus associados", proposta semelhante à antiga Sociedade ${ }^{12}$.
A criação desse movimento representou um ato de resistência dos negros quanto à imposição do governo, mantendo a proposta de trabalhar para efetivar a ascensão social e política desse grupo de pessoas. Dessa forma, Sebastiana Damião dos Santos, irmã de Pio Damião, assumiu o cargo de segunda tesoureira da Sociedade Negra Recreativa em novembro de 1955. Interessante notar que, assim como a elite dos fazendeiros se sucedia no poder, com a eleição de filhos e demais parentes para os cargos executivos e legislativos, o mesmo se deu com a família do personagem em foco.

Concomitantemente, Sebastiana Damião ministrava aulas de trabalhos manuais e participava da organização das festas e dos bailes promovidos para os associados e visitantes. Entre as festas mais relevantes estava a comemoração anual da abolição da escravatura, todo dia 13 de maio. Essa senhora esteve presente na reunião de maio de 1970 e foi referenciada em ata como a "primeira dama da sociedade" 12 , inequívoca transposição de valor cultural da classe dominante para o movimento negro. Note-se que não foi empregado qualquer referencial cultural de distinção hierárquica própria da cultura negra como, por exemplo, a do Candomblé, e sim a designação de epíteto usado no meio da política partidária e gestão do Estado.

Damião seguia a doutrina espírita, inclusive participou das primeiras reuniões de estudos do tema em Guaxupé no ano de 1925, embora o catolicismo fosse a religião dominante da época. Frise-se que a Santa
Casa foi idealizada pela elite guaxupeana com o apoio da Igreja Católica. Ele se dedicou à prestação de serviços no hospital até a chegada das Irmãs da Imaculada Conceição, em 1933, quando, provavelmente, a igreja católica não tenha aceitado sua permanência na instituição. As irmãs da caridade vieram para administrar a enfermagem do hospital e lá ficaram até a década de 1970.

0 catolicismo mantinha expressivo poder de enunciação e econômico através da íntima relação entre os membros do clero e as autoridades políticas da época. A influência da igreja no setor educacional, outra estratégia de dominação e manutenção do poder simbólico, teve início com a catequização indígena e, no setor saúde, desde a fundação das Santas Casas. Essa força política se manteve até o fim da Ditadura Militar e ainda hoje, porém, em menor escala, se faz presente ${ }^{13}$.

Não há registro do adoecimento de Pio Damião, mas o Jornal Folha do Povo anunciou seu falecimento no dia 26 de fevereiro de 1953, "portador de grave enfermidade, sendo vítima de insidiosa moléstia". Supõe-se que tenha morrido de câncer, pois essa era a linguagem característica da época para designar essa doença.

Posteriormente, a Câmara Municipal de Guaxupé, através da Lei n⿳0637, de 23 de agosto de 1974 $\mathrm{D} 3$, concedeu-lhe uma homenagem, nomeando uma rua na cidade de Guaxupé como seu nome. O logradouro situa-se próximo à sua antiga moradia e à Santa Casa, e está perpendicular a uma importante avenida da cidade, denominada Conde Ribeiro do Valle.

Damião foi reconhecido pela sociedade como um cidadão atuante, pertinaz na defesa dos negros, reivindicando direitos sociais e políticos de igualdade.

\section{CONCLUSÃO}

0 estudo permitiu resgatar a história de vida de um importante personagem guaxupeano. Homem simples, de origem modesta e estudos rudimentares, mas com valores morais elevados. Pio Damião conquistou posições no campo por meio da profissionalização e do exercício profissional 
em empresas de projeção como a Companhia Ferroviária e a Santa Casa de Guaxupé, onde contribuiu com o atendimento aos doentes internados e administrou os serviços de enfermagem desde os anos iniciais da sua fundação.

Por meio da Enfermagem amealhou capital econômico e obteve projeção política, administrando seus próprios empreendimentos, cuidando de pacientes portadores de diversas moléstias em sua própria residência e administrando a primeira empresa funerária da cidade.

Damião sofreu perseguição política, primeiro por conta da religião que praticava que não era prevalente na época e segundo, por ser de uma classe socioeconômica mais baixa e de uma raça que sofria (e sofre ainda) preconceito.Apesar dessas dificuldades, desenvolveu competências e somou realizações que o fizeram ser reconhecido como militante político atuante e de sucesso, por defender os negros com pertinácia e perseverança, para o que o exercício da Enfermagem muito contribuiu.

\section{Referências}

1. Valle JR, Valle GR, Ferreira MC, Ribeiro VV, Valle LER. Guaxupé: memória histórica - a terra e a gente. 2ed. Guaxupé:Gráfica Nossa Senhora de Fátima; 2004.

2. Ferraz WR. O capital que alavancou o progresso: o primeiro telefone, o primeiro banco, o primeiro trator de Guaxupé. Jornal Correio Sudoeste. 26 fev 2005; 1.734:8.

3. Porto F, Amorim WM. Escolas e Cursos de Enfermagem na História da Profissão no Brasil (1890-1922). Cultura de los Cuidados. Revista de Enfermería y Humanidades. 2010; 14(27): 40-5.

4. Mott ML. Revendo a história da enfermagem em São Paulo (1890-1920). Cadernos Pagu. 1999; (13):327-55.

5. Escudero L. Filhos da África em Guaxupé. Jornal da Escola Estadual Dr. Benedito Leite Ribeiro-Escola Viva. nov 2009; (2):4-5.

6. Valle JR. Inspeção sanitária do município de Guaxupé. (Guaxupé); jul 1931.

7. Jornal Cidade de Guaxupé, 24 fev 1924; 24:376:3.
8. Irmandade da Santa Casa de Misericórdia de Guaxupé. I Livro dos Enfermos da Santa Casa de Guaxupé (1923-1932). Manuscrito.

9. Typografia de obras da cidade de Guaxupé. Revista de Guaxupé. set. 1922; N esp. comemorativo ao Centenário da Independência.

10. Arquivo Público Mineiro. Arquivos da polícia política: acervo do período de 1927 a 1982 [Internet]. Belo Horizonte: APM; [200-] [citado em 10 jan 2015]. Disponível em: http://www.siaapm.cultura.mg.gov.br/modu les/dops/brtacervo.php?cid=4643.

11. Barbosa A, Lucrécio F, Leite JC, Ribeiro MO, Motta PD. Frente Negra Brasileira: depoimentos. São Paulo: Quilombhoje; 1998.

12. I Livro de Atas da Sociedade Negra Recreativa Pio Damião. Guaxupé, MG; 1954.

13. Fausto B. História Concisa do Brasil. São Paulo: Edusp; 2001.

\section{Referências Documentais}

$\mathrm{D}^{1}$. Irmandade da Santa Casa de Misericórdia de Guaxupé. Ata da Irmandade de Misericórdia do Hospital de Guaxupé. Guaxupé, MG; ago 1912.

$\mathrm{D}^{2}$. Registro de testamento público de Pio Damião. Regto no 71. D. ao $1^{\circ}$ Ofício. Guaxupé, MG; mar 1953.

$D^{3}$. Câmara Municipal de Guaxupé. Lei no637 de 23 de agosto de 1974. Dispõe sobre a denominação de ruas da cidade. Guaxupé, MG: CMG; 10 ago 1974.

$\mathrm{D}^{4}$. Irmandade da Santa Casa de Misericórdia de Guaxupé. Ata da sessão ordinária da mesa administrativa do Hospital de Guaxupé. Guaxupé MG; fev 1914.

$\mathrm{D}^{5}$. Cartório do $1^{\mathrm{o}}$ Ofício de Muzambinho. Autos de esboço de partilha-espólio do Dr. João Carlos de Magalhães Gomes. Muzambinho, MG; fev 1917.

$D^{6}$. Serviço Registral das Pessoas. Escritura pública de venda que Pedro José Vieira e sua mulher fazem a Pio Damião. Guaxupé, MG; nov 1915.

D7. Serviço Registral das Pessoas. Escritura pública de compra e venda que fazem José Maria de Souza e sua mulher a Pio Damião. Guaxupé, MG; jan 1917.

$\mathrm{D}^{8}$. Irmandade da Santa Casa de Misericórdia de Guaxupé. Ata da reunião da mesa 
administrativa da Santa Casa de Guaxupé. Guaxupé, MG; jul 1927.

D ${ }^{9}$. Irmandade da Santa Casa de Misericórdia de Guaxupé. Ata da Assembleia Geral Ordinária realizada no salão onde funcionava o Cinema Avenida para o fim de proceder-se a eleição da mesa administrativa que servirá no triênio de 1919-1921. Guaxupé MG; fev 1919.

$\mathrm{D}^{10}$. Irmandade da Santa Casa de Misericórdia de Guaxupé. Ata da sessão da Assembleia Geral Ordinária realizada no Salão do Teatro São Carlos para o fim de proceder-se a eleição da Diretoria que servirá no biênio de 1921 a 1922. Guaxupé MG; fev 1921.

$\mathrm{D}^{11}$. Irmandade da Santa Casa de Misericórdia de Guaxupé. Ata da Assembleia Geral realizada no salão do Clube Guaxupé para o fim de eleger-se nova Diretoria que servirá o biênio de 1923 a 1924. Guaxupé MG; abr 1923.

$\mathrm{D}^{12}$. Irmandade da Santa Casa de Misericórdia de Guaxupé. Ata da sessão extraordinária da diretoria da Santa Casa de Caridade de Guaxupé, para o fim de tratar de assuntos concernentes à parte financeira do mesmo Estabelecimento. Guaxupé MG; jul 1923.

\section{CONTRIBUIÇÕES}

Maria Regina Guimarães Silva e Maria Cristina Sanna tiveram iguais contribuições em todas etapas da elaboração do trabalhoconcepção, desenho, análise e interpretação dos dados. 